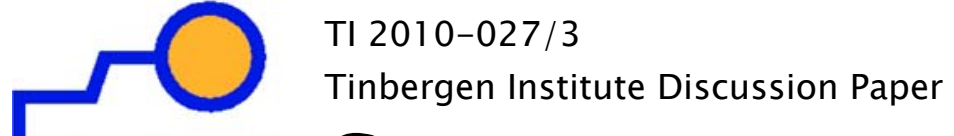 Can we measure Individual Risk Attitudes in a Survey?
}

\author{
Xiaohao Ding \\ Joop Hartog ${ }^{2}$ \\ Yuze Sun'
}

' Peking University;

2 University of Amsterdam, and Tinbergen Institute. 


\section{Tinbergen Institute}

The Tinbergen Institute is the institute for economic research of the Erasmus Universiteit Rotterdam, Universiteit van Amsterdam, and Vrije Universiteit Amsterdam.

Tinbergen Institute Amsterdam

Roetersstraat 31

1018 WB Amsterdam

The Netherlands

Tel.: +31(0)205513500

Fax: $+31(0) 205513555$

Tinbergen Institute Rotterdam

Burg. Oudlaan 50

3062 PA Rotterdam

The Netherlands

Tel.: + $31(0) 104088900$

Fax: $+31(0) 104089031$

Most TI discussion papers can be downloaded at http://www.tinbergen.nl. 


\title{
Can we measure individual risk attitudes in a survey?
}

\author{
Xiaohao Ding \\ Peking University \\ xhding@pku.edu.cn \\ Joop Hartog \\ University of Amsterdam \\ j.hartog@uva.nl \\ Yuze Sun \\ Peking University \\ sunyuze81@gmail.com
}

\begin{abstract}
We combine a survey and an experiment with real pay-out among Peking University students to measure and validate individual risk attitudes. The experiment involves choosing between a cash payment and playing a lottery. The survey questions ask for the reservation price of a hypothetical lottery and self-assessment of risk attitude on a 0-10 scale. We confirm familiar findings: risk aversion dominates, women are more risk averse than men, risk aversion decreases with increasing parental income, risk attitudes are domain-specific. Correlations between survey measures and experimental measures, are in the right direction, but not very high. The survey measures are valid indicators of experimentally measured risk attitude, but with substantial noise remaining. Heterogeneity in levels and structure of risk attitude is large.
\end{abstract}

JEL code: D12

Keywords: risk attitude; survey question; experimental validation

First draft: Summer 2008; this version 11-12-2009 


\section{Research Question}

Many questions in economics are analysed empirically with data collected in a survey. Risk attitude is often an important determinant of individual choice, but laboratory experiments to measure risk attitude are usually not feasible when data are collected by survey. Hence, it would be quite useful to have a reliable and validated method for measuring an individual's risk attitude in a survey. Recently, in economics two such methods have been put forward: asking for the reservation price of a hypothetical lottery ticket (Donkers et al., 2001; Hartog et al, 2002; Guiso and Paiella, 2008) and asking individuals to rate themselves on a scale of risk attitude, either in general or for specific domains of life (Dohmen et al., 2005). Both methods have been used to explain actual economic choices. Cramer et al. (2002) have used the lottery question to estimate the relationship between self-employment and risk attitude. Guiso and Paiella (2005) have used a lottery type question to relate risk attitude to employment status, financial investments and investment in human capital, Diaz-Serrano and O'Neil linked it to the probability of unemployment, Brunello (2002) linked it to attained level of education. Bonin et al. (2007) use the risk attitude scale to link risk attitude to employment in occupations differing by earnings risk, Caliendo et al. (2006) to link it to starting self-employment. Shaw (1996) and Budria et al. (2009) have used such scales to estimate the effect of risk attitude on wage growth (presumably resulting from investment in human capital, a risky asset). Apart from these two approaches, risk attitudes have also been measured by proxies like drinking and smoking behaviour (Bellante and Link, 1981, to explain public sector employment status). In psychology, there is a longer tradition of measuring risk attitudes in a survey (see, e.g. Weber et al., 2002).

In this paper we seek to validate these two methods by testing them on a real lottery, i.e. on a lottery with pay-out in real money. We set up an experiment among students of PKU in Beijing. We solicited their risk attitudes with both methods and presented them with four opportunities to participate in a real lottery which they could forgo by receiving a cash payment. We also asked them for demographic background information and some types of actual lifestyle behaviour.

Our work is very similar to Dohmen et al. (2005) ${ }^{1}$. They related answers to a hypothetical investment question to choices in a real lottery. The hypothetical question asked how much of 100 000 euro that had just been won in a lottery would be invested in an investment project that either doubles or halves the amount invested. Respondents were also offered choices between a "safe value" (a cash payment) and a specified lottery; successively increasing the safe value identifies the reservation price for the lottery. We essentially copied this approach and of course we will compare our outcomes to theirs. Apart from the fact that their results are for German adults and ours for Chinese students, there are two key differences. Dohmen et al. ask for hypothetical choice in an investment opportunity, we ask for the hypothetical reservation price of a lottery ticket; Dohmen et al. have 450 respondents, we only have 121 . The work by Fausto and Gillespie (2006) is also related. They focus on comparing measures of risk attitude collected in mail surveys, with extensive references to the literature and a test of their own among 75 cattle

\footnotetext{
${ }^{1}$ Binswanger (1980) also compares results of an actual and a hypothetical lottery, but he is more interested in learning behavour in repeated participation in a lottery game.
} 
farmers.

In the sequel, we present our questionnaire and experimental design (Section 2), we characterise the distributions of the key response variables (section 3), consider correlations between the risk attitude measures (section 4), compare success in predicting some types of behaviour (section 5 ) and relate measured risk attitudes to background characteristics (section 6). Section 7 concludes.

We have found that familiar findings are confirmed. As more or less commonly established in economics and psychology, risk aversion dominates and women are more risk averse than men. The economists' usual presumption that risk aversion decreases with increasing parental income is also found here. We find that risk attitudes are domain-specific, a common finding in psychology. But correlations between survey measures and experimental measures, while in the right direction, are low. A striking conclusion is the large heterogeneity in levels and structure of individual risk attitude.

\section{Survey and experimental design}

\subsection{The survey}

The computer programmed experiment took place in June 2008 at Peking University (PKU). Students were attracted to participate by announcements at the university intranet and in dormitories. Before the experiment, they are informed that participation would take about 40 minutes and that the basic payment is 20 Yuan. The respondents know they can earn more, but have no idea how and how much (which may imply some selectivity towards the less risk averse). The project consisted of two parts: a questionnaire and a set of experiments. A respondent was first required to complete the questionnaire and then to participate in four games, each providing choice between a cash payment and participating in a lottery. 121 students signed up, third-year and mostly fourth-year students. On average they took home 135 yuan, with a minimum of 60 and a maximum of 620 yuan. These are substantial amounts for students. A survey among more than 50 Beijing universities in 2008 found a median monthly income of 716 yuan, making the average take-home from the experiment close to $20 \%$ of median monthly income ${ }^{2}$.

The questionnaire used for the survey has six sections:

$\square 1 \square \quad$ Risk attitude (willingness to pay for a lottery, risk aversion scales)

$\square 2 \square$ Personal data (demographics, major etc).

$\square 3 \square$ Career choice (career orientation, graduate job placement. .

( $4 \square$ Postgraduate education choice (pursue postgraduate study, views about financial support)

$\square 5 \square$ Lifestyle (smoking, drinking, etc)

\footnotetext{
${ }^{2}$ The survey was conducted by one of us (Xiaohao Ding).
} 
$\square 6 \square$ Expected future income, for different schooling choices

The data from section 4 and section 6 will be analysed in a separate paper. Table 1 shows basic information about respondents. The sample is about equally divided between male and female respondents, they are well spread across majors, most students are from more or less urban areas; and their family background, measured by education and income, might be characterised as mostly middle-class. Self-assessed rank in academic performance shows the usual over-estimation of quality. We will still use it, assuming that the ranking is not wholly unrelated to true ranking.

\subsection{Measuring risk attitude by survey}

We measure risk attitude by survey in two ways: the reservation price for a lottery ticket and by self-assessment on a given scale.

A lottery question asks the respondent to specify the maximum price to be paid for participation in a specified hypothetical lottery. As noted, this approach was applied earlier in Hartog, Ferrer-iCarbonell and Jonker (2002) and in a survey of the Bank of Italy (Guiso and Paiella, 2008). We refer to this question as the lottery question. Specifically, in the present survey we ask:

Suppose in a lottery game, the possibility to win 1,000 yuan is $10 \%$, then how much would you pay at most to buy a lottery ticket?

We refer to the answer as the Lottery Reservation Price.

We have also reversed the question:

Now we change the conditions of the choice. Suppose you are offered 100 yuan in cash. Instead, however, you may choose a lottery ticket. The lottery has a prize of 2000 yuan, but the probability to win has not yet been determined. We want you to think about different probabilities to win the prize of 2000 yuan. How high should this probability be at least for you to take the lottery ticket rather than the 100 yuan in cash?

We refer to the answer as the Lottery Reservation Probability. We have given the two lotteries different specifications, so as not to stimulate respondents to derive answers for the second question from the specification of the first question.

For risk attitude measurement by self-assessment we copy the questions asked in the German SOEP survey, and analysed in Dohmen et al. (2005). Following a common practice, they ask individuals to grade themselves, on an eleven-point scale:

How do you see yourself: Are you in general a person who takes risk or do you try to evade risks? Please self-grade your choice (ranging between 0-10)

The grades run from 0: "not at all prepared to take risk" to 10: "very much prepared to take risk". The same question has been asked for five domains:
A. finances;
B. leisure;
C. career; 

D. health;
E. education.

\subsection{Measuring risk attitude experimentally}

To measure risk attitude experimentally, we present the students with choices between receiving a cash payment or playing a lottery, with real pay-out. There were four such games. To make sure all games are attended, students are informed that the choices in each game will contribute to their final payment. To restrain the cost of the experiment, actual pay-out only takes place randomly for one of the four games.

The choices in the games are presented on the student's computer screen. For Game 1, this runs as follows:

We will now offer you a choice between playing a lottery or receiving an amount of money. We will ask you 20 times to choose between an amount of money and the lottery. Each time the lottery is the same, but the amount of money is different. After you have made your choice in all 20 cases, one of these alternatives will be randomly selected.

If in the selected alternative you have indicated you prefer the money, we will pay you the amount that was stated.

If you have indicated that you prefer the lottery, we will play the lottery. If you win, the prize will be sent to you by check right after this session.

In the lottery, with $50 \%$ probability you will win 300 yuan, with $50 \%$ probability you will receive nothing.

The computer screen shows the options as in Table 2, with a maximum of 20 choices. The cash payment for each option increases from 10 yuan to 200 yuan. The value is raised as long as the student chooses to continue the game. If in option 20 the student has not preferred a cash payment, the lottery will be played as indicated if the random draw would pick this choice option. The screen imposes consistency: if a student switches from preferring the lottery to the cash pay-out, all lower entries show that the lottery is preferred, all higher entries show that the cash pay out is preferred. Respondents can always change all their entries as long as they have not yet submitted their response to all four games. We will call this game the 300 Yuan Lottery Game. We will call the cash pay-out where the respondent switches to preferring the pay-out to the lottery the 300 Yuan Game Reservation Price. In the second game we only change the lottery options: a $25 \%$ probability to win 600 yuan and $75 \%$ to win nothing; we will call this the 600 Yuan Lottery Game and the switch point the 600 Yuan Game Reservation Price.

In Game 3 and 4 we ask for reservation probabilities. In Game 3, respondents can choose between receiving 20 yuan or participate in a lottery with a prize of 100 yuan, where the probability of winning varies; we call this the Win 100 yuan game and the switching probability the Win 100 Yuan Reservation Probability. In Game 4, respondents receive 100 yuan and then are offered the choice to pay 20 yuan or play a lottery with prize of -100 yuan, i.e., the obligation to pay 100 yuan. We call this the Loose 100 Yuan Game and the switching probability the Loose 100 Yuan Reservation Probability. 


\section{Outcomes: frequency distributions}

Graphs 1 to 12 depict the frequency distributions for the 12 measures of risk attitude: the 2 lottery questions, the 6 self assessed scaling measures and the 4 games. The graphs demonstrate substantial heterogeneity in risk attitudes. With one exception, in each distribution the mode has less than $30 \%$ of the observations. Most distributions even have a modal value below $20 \%$. The exception is the lottery reservation price where almost half the respondents quote the expected value.

Self-scaling generates more refined information than asking for reservation prices and probabilities, in the sense that responses are more spread out over potential values. In Graph 1, for the lottery reservation price, we see clear bumping. Almost half the respondents value the lottery ticket at expected value, and there are two more spikes, at 5 and 50 yuan. The lottery reservation probability has more variation. The mode is still at the probability corresponding to expected value (5\%), but there is clear concentration at some multiples of 10 points. In the lottery reservation price, three quarters of the answers are concentrated at just three values. There is slightly less bumping in the reservation probability question, in the sense that it now takes four values to get up to three quarters of the respondents. The distributions of self-scaled risk attitude (Graphs 3 to 8 ) tend towards more or less regular single-peaked distributions, but with marked differences.

Risk attitudes are domain specific. Self-assessed risk attitudes clearly deviate from a symmetric single-peaked distribution for leisure and for health. In leisure, respondents lean heavily towards risk taking, in health they lean heavily towards risk aversion. This result deviates from Dohmen et al. who find respondents most risk averse in financial matters and most risk taking in general risk attitude and then in career and leisure risk, judged by the average scores on the scales (o.c. Table 4). Remarkably then, their respondents are not most averse in the domain of health, as one might intuitively have anticipated and as our Chinese students indeed are.

In Table 3, we show the distribution of responses across three categories: risk averse, risk neutral, risk loving. For the reservation price, risk averse is defined as having a reservation price below the expected value, for the reservation probability as having a reservation probability above the probability that equates the cash payment to the expected value of the lottery (or below it for the Loose 100 Yuan Game). For the risk attitude scales, risk neutrality is not precisely defined and hence we cannot compare with results for the other measures in a precise way. We will define a score of 5 , neatly in the middle of the scale, as risk neutrality, for illustrative purposes.

Measured by the lottery question and three of the four games, most respondents are not risk loving. With exception of the lottery reservation price noted earlier, risk aversion is the rule, with remarkably similar scores for three measures. In the Loose 100 Yuan Game, risk loving dominates. This confirms risk seeking in case of losses as stressed in prospect theory.

Risk aversion does not dominate in the self-assessment, but this statement must be conditioned by the arbitrary definition of risk neutrality in this case ${ }^{3}$. The results for self-assessed risk attitude

\footnotetext{
${ }^{3}$ Note that the absence of skew cannot be interpreted as absence of dominant risk aversion, as we cannot rule out that the mode of the distribution lies below risk neutrality.
} 
again indicate that risk attitudes are domain specific, perhaps even more succinctly than was indicated by the full frequency distributions. At the chosen scale three quarters of the respondents is risk loving in leisure, while in matters of health three quarters is risk averse. General risk attitudes are quite close to those in finance and career, whereas in education respondents are a bit more risk averse. The view that risk attitude is domain specific is widely held among psychologists, though not universally (Slovic, 1972a; 1972b; see the discussion in Weber et al., 2002). Fausto and Gillespie (2006) also find sensitivity to context.

The 300 and 600 Yuan Games yield fairly similar distributions of risk types, although willingness to take risk is slightly higher when the prize is higher. The distribution for the Win 100 Yuan reservation probability is also remarkably similar.

Variation of risk attitude across domains can also be studied by looking at the fraction of respondents who are the same type across domains. Graph 13 shows that 3 students or $2.5 \%$ choose willingness to take risk in all 6 questions; $13.2 \%$ reply so to 5 questions; $18.2 \%$ to 4 questions; $66.1 \%$ to 3 questions or less. By that standard, the assumption of homogeneity of risk attitude across domains does not hold water either. Dohmen et al. (p. 23) report much stronger consistency across domains: $51 \%$ is willing to take risk (scores above 5 ) in all six domains. This score is very high compared to $78 \%$ risk averse individuals in their experiment (and $9 \%$ risk lovers, o.c. p 17).

We also asked participants whether they preferred the 300 Yuan Game or the 600 Yuan Game; both games have an expected value of 150 yuan, but probabilities differ. Most respondents are willing to take more risk when the potential return is higher. At the same expected value but higher probability to draw the zero, $62 \%$ of respondents prefer the 600 Yuan Game to the 300 Yuan Game.

\section{Outcomes: Correlations}

Table 4 gives the common correlation coefficients and the rank correlation coefficients among all 12 measures of risk attitude. Correlations between ranks are not uniformly larger than between values: one scale is not clearly superior to the other. The table supports several conclusions,

The correlation between the 300 and the 600 Yuan Games is high, in fact the highest in each table. This indicates that reservation prices for lotteries with different stakes give fairly similar information. Asking for reservation probability rather than reservation price gives different information, as is also indicated by the low correlation between lottery reservation price and lottery reservation probability. When we differentiate between winning or loosing 100 yuan, correlations are again lower, in particular for loosing. This adds to heterogeneity: asymmetry in the evaluation of loosing and winning is also quite heterogeneous.

The correlations among the four specific domains of self-assessed risk attitude are low. The highest value, 0.55 , is obtained for risk attitudes in career and in education. This means that no more than 30 percent of the variance in one domain is explained by risk attitude in another domain. This result does not deviate much from Dohmen et al. The correlations they find among five domains are generally higher than what we find (around 0.5), but their maximum value is 0.6 , 
indicating that at most 36 percent of the variance is explained. Correlations in Fausti and Gillespie (2006) are not higher. This reinforces the conclusion from the literature we cited earlier: risk attitudes are domain specific.

The two survey methods do not correlate very strongly. The two lottery questions correlate at 0.15 and 0.12 with general risk attitude. This is lower than in Dohmen et al.: the answer to their hypothetical investment question correlates at 0.26 with risk attitude in general, which is not very strong either. Extending the comparison to include domain specific attitudes, we find that the answers to the lottery questions correlate strongest with risk attitude in finance, a conclusion that certainly makes sense. General risk attitude correlates most with risk attitude in finance, in career and in education, least with risk attitude in leisure and in health. (Dohmen et al. find highest correlations with career and with leisure).

The key goal of this project is to validate survey risk attitude questions on revealed risk attitudes in a situation where real money is at stake. Correlations between the games and the general survey measures are in the right direction and generally statistically significant, and in that sense the survey measures are valid predictors of risk attitude in a real-money situation. But they are not very precise: at best they explain 10 percent of the variance. Self-assessed domain specific risk attitudes generally predict much worse, except for risk attitude in finance (which correlates fairly well with general risk attitude).

To compare the performances of the lottery question and self-assessed risk attitude, we only have to consider results for general risk attitude, as this always predicts better than domain specific risk attitudes. The lottery reservation price predicts markedly better than the lottery reservation probability, except when it comes to predicting the reservation probability in a real-money game. Note that the real-money reservation probability for loosing 300 yuan is better predicted better by the reservation lottery price than by the reservation lottery probability, which is remarkable. Self-assessed risk attitude generally predicts best, but not unequivocally. Some margins are quite small. The gaps are largest when the real-money game explicitly specifies a lottery with either winning or loosing 100 yuan.

The general conclusion is quite similar to Dohmen et al. Survey measures predict measures found in experimental real-money data, but far from precisely. We find correlations of the lottery reservation price of .21 with the reservation price for the 300 Yuan Game and .27 for the 600 Yuan Game, while rank correlations are .26 for both. Dohmen et al. (o.c. Table 2 b) report a squared correlation coefficient of .06 for a linear regression of the experimental lottery reservation price on general risk attitude, i.e. a correlation coefficient of .24. We cannot compare with the hypothetical investment proportion, as this correlation is not reported. Neither are there correlations with domain specific risk attitudes and experimental valuations.

\section{Predicting behaviour}

In the survey, we asked for information on seven lifestyle behaviours: drinking, smoking, taking vitamin pills, buying lottery tickets, buying stocks, practice rock climbing and exam preparation. 
For students living on a campus in China, it is not easy to single out behaviours for which risk attitude is important, and this is about the best we could come up with. Taking vitamin pills to influence health status, drinking alcohol and buying stocks or lottery tickets are not very common. But it is the best we could think of. We try to explain these risk related behaviours from our 12 risk attitude measures, with a logit model when there were essentially two options (most questions had three response categories, but in several cases the frequencies on one of these was zero or very low; in that case we merged them) or an ordered probit. We use only risk attitude as independent variable; we might have added other independent variables (such as gender, family background), but most of these must be expected to have some relationship with risk attitude as well. We would then get involved in questions of endogeneity and direction of causation. Instead, we opted for a simple comparison of explained variance by each risk attitude measure as a single regressor. Results are in Table 5. Note that some of these risky behaviours have also been used in the literature as variables to measure risk attitude, rather than as variables to be explained.

Explanatory power of our risk attitude measures, as indicated by significance levels and proportion of variance explained, is quite low. The behaviour that is best explained is willingness to participate in rock climbing, apparently the type of behaviour that is most differentiated by risk attitude. The risk measure with the best prediction score is the general risk attitude measure. Rock climbing is best predicted by risk attitude in leisure, but in fact the difference with general risk attitude is zero. Among the real-money measures, the Win/Loose 100 Yuan Games predict best, but at substantially lower correlations. There is also some success in predicting the nature of exam preparation ("do you work so hard that you will be almost sure to pass" versus "hope they just ask what you happen to know"). The best predictor is not risk attitude in education but in leisure, an answer that will not make many teachers happy.

The lottery questions have virtually no predictive power for the risky behaviours we selected, and the real-money experiments only have some power to predict rock climbing. The results again show traces of domain specificity, considering the significant correlations of drinking and rock climbing with risk taking in leisure, of smoking with risk taking in health, of exam preparation with risk taking in education and of buying stocks with risk taking in finance. But these correlations are not always the highest for a given behaviour.

\section{Relating risk attitude to personal characteristics.}

In Table 6, we show regression results for all 12 measures of risk attitude in relation to personal characteristics: gender (female), major ( 2 dummies), family income (4 dummies) and self-assessed study rank ( 3 dummies). We applied OLS for all regressions including the self assessed scales; for the latter we did not choose an ordered response model, as the outcomes do not differ much from OLS and interpretation of coefficients is less straightforward. Note that increasing risk aversion would be indicated by negative effects on the lottery reservation price, on the risk attitude scales, on the 300 and 600 Yuan lottery games and on the Loose 100 Yuan reservation probability, and by positive effects on the lottery reservation probability and the Win 100 Yuan reservation probability (in case of dummies, the direction of the effect follows from comparing dummy coefficients, i.e. increasing or decreasing across categories). Hence, consistency of effects on all measures requires identical signs in coefficient columns 1, 3-10 and 12, and opposite signs in 
columns 2 and 11.

Estimated coefficients are very imprecise, presumably at least to some extent on account of the modest sample size. Some standard results from the literature are confirmed. Women are more risk averse than men: all but one of the signs of the coefficients point in the same direction, although the effect is significant only for risk attitude in finance. The exception is the positive effect on the Loose 100 Yuan game. The effects of major are not consistently in the same direction. Most remarkable is the significantly lower risk aversion for students in the humanities compared to those in technical studies in general and financial risk attitude; however, the results on the lottery reservation probability point significantly to higher risk aversion for students in humanities. The effect of increasing family income mostly works in the anticipated direction, with risk aversion declining as family income increases. Exceptions are the results for risk attitude in matters of health, the 600 Yuan lottery game and the Loose 100 Yuan game. Also, the highest income category does not always neatly fit in the sequence of coefficients. Self-assessed study rank significantly affects general and financial risk attitude: those assessing themselves above the lowest quartile (some 93\%!) are more risk averse. The effects are in the same direction for the other risk attitude scales, except in matters of health. In fact, those who consider themselves to be in the top $25 \%$ ( $34 \%$ of the sample) are fairly consistently more risk averse than those who rank themselves lower; the exceptions are health risk attitude, the 600 Yuan lottery game and the Win 100 Yuan game.

The outcomes for the 300 and the 600 Yuan lottery game are quite close in the qualitative sense (direction of effects); magnitudes of effects show greater difference, without reflecting a simple scaling factor. Judged by the direction of effects of personal characteristics, the lottery reservation price does not perform worse than general risk attitude. Results of general risk attitude are very similar to results for financial risk.

Generally we may conclude that the results are in line with intuition or results found earlier in the literature, but that coefficients are estimated with very little precision.

\section{Conclusion}

Simple survey questions to assess risk attitudes, like hypothetical lottery questions or self-scaling, appear to generate valid indicators of choices under risk in an experimental set-up where real money is at stake. Correlations have the proper sign and are often statistically significant. But the precision of the predictions is not high. This finding is not related to the modest number of participants in our experiment. Correlations between survey measures and experimental real-money measures among our 121 participants are not substantially lower than among the 450 participants in the similar experiment conducted by Dohmen et al. (2005); the magnitudes are also similar between different survey measures elicited from 75 cattle farmers in Fausti and Gillespie (2006).

The results point to a combination of large heterogeneity and domain specificity (or context sensitivity) of attitudes. Heterogeneity in risk attitudes manifested in choices with real consequences is clear from the dispersion in the results for the real-money experiments. Domain sensitivity is clear from the low inter-correlations for self-assessed risk attitude in the five different 
domains we distinguish. Presumably, there is heterogeneity in other dimensions as well. Reservation prices and reservation probabilities for the same individual do not correlate strongly and neither do reservation probabilities for winning or loosing the same amount. While simple survey questions do generate valid indicators of risk attitudes measured experimentally, the multi-faceted heterogeneity renders the simplifications in the survey questions probably too strong. Even though self-assessed general risk attitude often predicts comparatively well, it may be well-advised to make these survey instruments context specific, geared to the problem at hand.

Finally, we may note that we have found confirmation of several regularities that have been established in the literature. Risk aversion is by far the dominant type of behaviour, but risk lovers do exist. In the 300 and 600 Yuan Games, over $20 \%$ of participants behave as risk lovers and value the lottery above its expected pay-out. Respondents behave mostly as risk lovers in case of loss avoidance. We find women to be more risk averse than men and risk aversion declining with family income. Domain specificity of risk attitude is also well established in the literature. Our Chinese students lean strongly towards risk aversion in the health domain and towards risk loving in the domain of leisure, which seem very plausible results. 


\section{References}

[1] Barsky, R. B., T. F. Juster, M. S. Kimball, and M. D. Shapiro (1997), Preference Parameters and Individual Heterogeneity: An Experimental Approach in the Health and Retirement Study, Quarterly Journal of Economics, 112(2), 537-579

[2] Bellante, D. and A. Link (1981), Are public sector workers more risk averse than private sector workers?, Industrial and Labor Relations Review, 34(3), 408-412

[3] Binswanger, H. (1980), Attitudes toward risk: experimental measurement in rural India, American Journal of Agricultural Economics, 62, 395-407

[4] Bonin, H., T. Dohmen, A. Falk, D. Huffman and U. Sunde (2007), Cross-sectional Earnings Risk and Occupational Sorting: The Role of Risk Attitudes, Labour Economics, 14(6), 926-937

[5] Brunello, G. (2002), Absolute risk aversion and the returns to education, Economics of Education Review, 21(6), 635-640

[6] Budria, S., L. Diaz Serrano, A. Ferrer-i-Carbonell and J. Hartog (2009), Risk attitude and wage growth: replication and reconstruction, IZA Discussion Paper 4124

[7] Caliendo, M., Fossen, F.M., Kritikos, A.S. (2006): “Risk Attitudes of Nascent Entrepreneurs: New Evidence from an Experimentally Validated Survey", IZA Discussion Paper, No. 2168

[8] Camerer, C. (1995), Individual decision making, in: J.Kagel and A. Roth, editors, Handbook of Experimental Economics, Princeton, NJ: Princeton University Press.

[9] Cramer, J.S., Hartog, J., Jonker, N., van Praag, C.M. (2002), Low risk aversion encourages the choice for entrepreneurship: an empirical test of a truism, Journal of Economic Behavior and Organization, 48 (1), 29-36.

[10] Diaz-Serrano, L., and D. O'Neill (2004): “The Relationship Between Unemployment and Risk-Aversion", IZA Discussion Paper No. 1214.

[11] Dohmen, T., A. Falk, D. Huffman, U. Sunde, J. Schupp and G. Wagner (2005), Individual Risk Attitudes: New Evidence from a Large, Representative, Experimentally-Validated Survey, IZA Bonn, DP 1730.

[12] Donkers, B., B. Melenberg, and A. V. Soest (2001), Estimating Risk Attitudes Using Lotteries: A Large Sample Approach, Journal of Risk and Uncertainty, 22(2), 165-195.

[13] Fausti, S. and J. Gillespie (2006), Measuring risk attitude of agricultural producers using a mail survey: how consistent are the methods?, Australian Journal of Agricultural and Resource Economics, 50(2), 171-188,

[14] Guiso, L., and M. Paiella (2005), The Role of Risk Aversion in Predicting Individual Behavior, Bank of Italy Economic Working Paper No. 546.

[15] Guiso, L., and M. Paiella (2008), Risk Aversion, Wealth, and Background Risk, Journal of the European Economic Association, 6(6), 1109-1150,

[16] Hartog, J., A. Ferrer-i-Carbonell and N. Jonker (2002), Linking measured risk aversion to individual characteristics, Kyklos, 55 (1), pp. 3-26

[17] Shaw, K.L. (1996), An empirical analysis of risk aversion and income growth, Journal of Labor Economics, 14 (4), 626-653.

[18] Weber, E., A. Blais and E. Betz (2002), A domain-specific risk attitude scale: measuring risk perceptions and risk behaviors, Journal of Behavioral Decision Making, 15,263-290 
Table 1 Basic information about respondents

\begin{tabular}{|c|c|c|c|}
\hline Variable & Percentage & Variable & Percentage \\
\hline Year of birth & & CPC Membership & \\
\hline 1984 & $2.5 \%$ & Yes & $33.9 \%$ \\
\hline 1985 & $33.9 \%$ & No & $66.1 \%$ \\
\hline 1986 & $47.1 \%$ & Student Loan Application & \\
\hline 1987onward & $16.5 \%$ & Yes & $38.8 \%$ \\
\hline Gender & & No & $61.2 \%$ \\
\hline Male & $50.4 \%$ & $\begin{array}{l}\text { Family income (per family } \\
\text { member) }\end{array}$ & \\
\hline Female & $49.6 \%$ & $<5,000$ yuan & $26.4 \%$ \\
\hline Majors & & $5,000-20,000$ yuan & $38.8 \%$ \\
\hline Philosophy & $1.7 \%$ & $20,000-50,000$ yuan & $19.8 \%$ \\
\hline Economics & $9.9 \%$ & $50,000-100,000$ yuan & $9.9 \%$ \\
\hline Law & $16.5 \%$ & $>100,000 y u a n$ & $5.0 \%$ \\
\hline Literature & $14.0 \%$ & Father's education level & \\
\hline History & $5.0 \%$ & Primary school & $2.5 \%$ \\
\hline Science & $42.1 \%$ & Junior high school & $15.7 \%$ \\
\hline Engineering & $3.3 \%$ & Senior high school & $26.4 \%$ \\
\hline Administration Science & $7.4 \%$ & $\begin{array}{l}\text { Secondary } \\
\text { vocation/technical school }\end{array}$ & $0.8 \%$ \\
\hline Hometown Residence & & Three-year college & $19.8 \%$ \\
\hline City & $52.9 \%$ & University & $29.8 \%$ \\
\hline Provincial town & $28.9 \%$ & Postgraduate & $5.0 \%$ \\
\hline Rural town & $6.6 \%$ & Mother's educational level & \\
\hline Village & $11.6 \%$ & Primary school and below & $11.6 \%$ \\
\hline $\begin{array}{ll}\text { Academic } & \text { Ranking } \\
\text { (self-assessed) } & \end{array}$ & & Junior high school & $15.7 \%$ \\
\hline Top 25\% & $33.9 \%$ & Senior high school & $29.8 \%$ \\
\hline Middle-upper $25 \%$ & $33.1 \%$ & $\begin{array}{l}\text { Secondary } \\
\text { vocation/technical school }\end{array}$ & $9.1 \%$ \\
\hline Middle-lower 25\% & $25.6 \%$ & Three-year college & $15.7 \%$ \\
\hline Bottom 25\% & $7.4 \%$ & University & $14.9 \%$ \\
\hline Mother's career & & Postgraduate & $3.3 \%$ \\
\hline Administration & $4.1 \%$ & Father's career & \\
\hline Manager & $1.7 \%$ & Administration & $12.4 \%$ \\
\hline Clerk in enterprise & $23.1 \%$ & Manager & $6.6 \%$ \\
\hline $\begin{array}{l}\text { technician/professional } \\
\text { employee }\end{array}$ & $10.7 \%$ & Clerk in enterprise & $24.8 \%$ \\
\hline Personal business employee & $8.3 \%$ & $\begin{array}{l}\text { technician/professional } \\
\text { employee }\end{array}$ & $10.7 \%$ \\
\hline Service industry employee & $0.8 \%$ & $\begin{array}{l}\text { personal } \\
\text { employee }\end{array}$ & $11.6 \%$ \\
\hline
\end{tabular}




\begin{tabular}{llll}
\hline private business owner & $0.8 \%$ & private business owner & $4.1 \%$ \\
Worker & $4.1 \%$ & Worker & $6.6 \%$ \\
Farmer & $13.2 \%$ & Farmer & $12.4 \%$ \\
Retirees & $20.7 \%$ & Retirees & $5.0 \%$ \\
Unemployed & $10.7 \%$ & Unemployed & $3.3 \%$ \\
Other & $1.7 \%$ & Other & $2.5 \%$ \\
\hline
\end{tabular}


Table 2. Screen showing game choices in the experiment

\begin{tabular}{|l|l|}
\hline choice number & \\
\hline 1 & $\square$ I choose 10 yuan $\quad$ I I choose to play the game \\
\hline 2 & $\square$ I choose 20 yuan $\quad$ I choose to play the game \\
\hline 3 & $\square$ I choose 30 yuan $\quad$ I l choose to play the game \\
\hline 4 & $\square$ I choose 40 yuan $\quad$ I choose to play the game \\
\hline 5 & $\square$ I choose 50 yuan $\quad$ I choose to play the game \\
\hline$\square \square \square$ & $\square \square$ \\
\hline 15 & $\square$ I choose 150 yuan $\quad$ I I choose to play the game \\
\hline 16 & $\square$ I choose 160 yuan $\quad$ I choose to play the game \\
\hline 17 & $\square$ I choose 170 yuan $\quad$ I l choose to play the game \\
\hline 18 & $\square$ I choose 180 yuan $\quad$ I l choose to play the game \\
\hline 19 & $\square$ I choose 190 yuan $\quad$ I l choose to play the game \\
\hline 20 & $\square$ I choose 200 yuan $\quad$ I l choose to play the game \\
\hline
\end{tabular}


Table 3 Distribution of risk attitudes by measure

\begin{tabular}{|l|l|l|l|}
\hline & Risk averse & Risk neutral & Risk lover \\
\hline Lottery reservation price & 39.7 & 46.3 & 14.0 \\
\hline Lottery reservation probability & 69.0 & 28.0 & 3.0 \\
\hline Risk attitude scales & & & \\
\hline General & 40.5 & 13.2 & 46.3 \\
\hline Finance & 41.3 & 17.4 & 41.3 \\
\hline Leisure & 14.0 & 9.9 & 76.1 \\
\hline Career & 38.0 & 16.5 & 45.5 \\
\hline Health & 76.9 & 9.9 & 13.2 \\
\hline Education & 48.8 & 19.0 & 32.2 \\
\hline 300 Yuan Game reservation price & 67.0 & 11.5 & 21.5 \\
\hline 600 Yuan Game reservation price & 60.3 & 18.4 & 21.3 \\
\hline Win 100 Yuan reservation probability & 69.0 & 16.0 & 15.0 \\
\hline Loose 100 Yuan reservation probability & 35.0 & 14.0 & 51.0 \\
\hline
\end{tabular}


Table 4A Correlation Matrix, measures of risk attitude

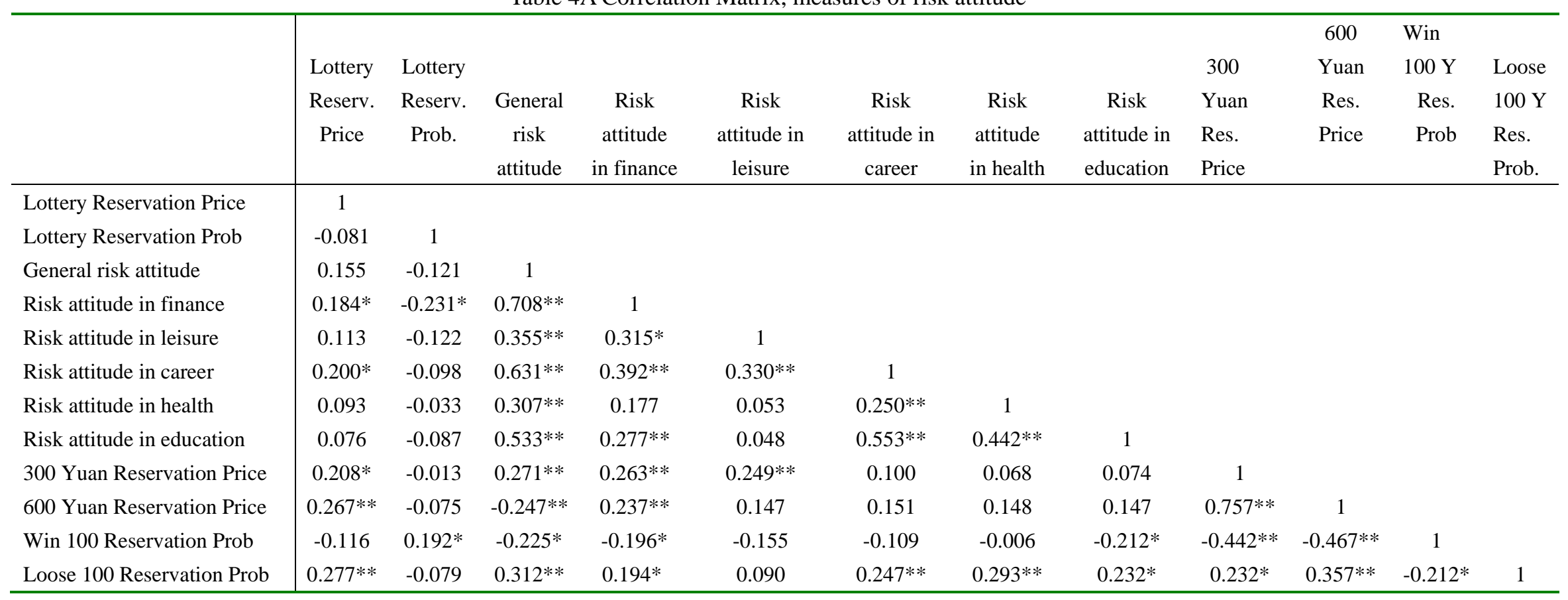




\begin{tabular}{|c|c|c|c|c|c|c|c|c|c|c|c|c|}
\hline & $\begin{array}{c}\text { Lottery } \\
\text { Res.Price }\end{array}$ & $\begin{array}{c}\text { Lottery } \\
\text { Res. } \\
\text { Prob. }\end{array}$ & $\begin{array}{c}\text { General } \\
\text { risk } \\
\text { attitude }\end{array}$ & $\begin{array}{c}\text { Risk } \\
\text { attitude } \\
\text { in } \\
\text { finance }\end{array}$ & $\begin{array}{c}\text { Risk } \\
\text { attitude in } \\
\text { leisure }\end{array}$ & $\begin{array}{c}\text { Risk } \\
\text { attitude in } \\
\text { career }\end{array}$ & $\begin{array}{c}\text { Risk } \\
\text { attitude } \\
\text { in health }\end{array}$ & $\begin{array}{c}\text { Risk } \\
\text { attitude in } \\
\text { education }\end{array}$ & $\begin{array}{l}300 \mathrm{Y} \\
\text { Res. } \\
\text { Price }\end{array}$ & $\begin{array}{c}600 \text { Y } \\
\text { Res.Price }\end{array}$ & $\begin{array}{l}\text { Win } \\
100 Y \\
\text { Res. } \\
\text { Prob }\end{array}$ & $\begin{array}{c}\text { Loose } \\
100 \mathrm{Y} \\
\text { Res. } \\
\text { Prob. }\end{array}$ \\
\hline Lottery Reservation Price & 1 & & & & & & & & & & & \\
\hline Lottery Reservation Prob. & $-0.304 * *$ & 1 & & & & & & & & & & \\
\hline General risk attitude & 0.153 & -0.119 & 1 & & & & & & & & & \\
\hline Risk attitude in finance & $0.260 * *$ & $-0.208 *$ & $0.705^{* *}$ & 1 & & & & & & & & \\
\hline Risk attitude in leisure & 0.135 & -0.148 & $0.372 * *$ & $0.328 * *$ & 1 & & & & & & & \\
\hline Risk attitude in career & 0.119 & -0.053 & $0.606 * *$ & $0.390 * *$ & $0.348 * *$ & 1 & & & & & & \\
\hline Risk attitude in health & 0.035 & 0.032 & $0.318^{* *}$ & $0.209 *$ & -0.008 & $0.222 *$ & 1 & & & & & \\
\hline Risk attitude in education & 0.074 & -0.018 & $0.534^{* *}$ & $0.289 * *$ & 0.070 & $0.523^{* *}$ & $0.431^{* *}$ & 1 & & & & \\
\hline 300 Y Res. Prob & $0.262 * *$ & -0.145 & $0.279 * *$ & $0.250 * *$ & $0.216^{*}$ & 0.078 & 0.103 & 0.069 & 1 & & & \\
\hline 600 Y Res. Prob & $0.267 * *$ & -0.067 & $0.253^{* *}$ & $0.228 *$ & -0.151 & 0.146 & 0.165 & 0.167 & $0.755^{* *}$ & 1 & & \\
\hline Win 100 Y Res. Prob. & -0.160 & $0.267 * *$ & $-0.237 * *$ & $-0.195 *$ & -0.157 & -0.086 & -0.014 & $-0.203^{*}$ & $-0.435 * *$ & $-0.441^{* *}$ & 1 & \\
\hline Loose 100 Y Res. Prob. & 0.173 & -0.028 & $0.317 * *$ & 0.162 & 0.099 & $0.231^{*}$ & $0.249 * *$ & $0.202 *$ & 0.149 & $0.292 * *$ & -0.134 & 1 \\
\hline
\end{tabular}

*. Correlation is significant at the 0.05 level (2-tailed)

**. Correlation is significant at the 0.01 level (2-tailed). 
Table 5 Explaining lifestyle behaviours from risk attitude measures

\begin{tabular}{|c|c|c|c|c|c|c|c|}
\hline & (1)Drinking & (2)Smoking & (3)Taking Vitamin & (4)Lottery tickets & (5)exam preparation & (6)Stocks & (7)Rock climbing \\
\hline \multicolumn{8}{|l|}{ Lottery Res. } \\
\hline \multirow[t]{2}{*}{ Price } & 0.000 & -0.001 & -0.002 & -0.002 & -0.001 & 0.000 & 0.000 \\
\hline & $(0.000)$ & $(0.008)$ & $(0.023)$ & $(0.044)$ & $(0.010)$ & $(0.000)$ & $(0.001)$ \\
\hline \multicolumn{8}{|l|}{ Lottery Res. } \\
\hline \multirow[t]{2}{*}{ Prob. } & -0.001 & -0.011 & -0.004 & -0.009 & $0.034^{*}$ & -0.002 & 0.008 \\
\hline & $(0.000)$ & $(0.009)$ & $(0.001)$ & $(0.008)$ & $(0.064)$ & $(0.000)$ & $(0.007)$ \\
\hline \multirow{2}{*}{$\begin{array}{l}\text { General risk } \\
\text { attitude }\end{array}$} & $-0.158 *$ & $-0.340 * *$ & -0.058 & 0.038 & $-0.260 * *$ & $-0.309 * * *$ & $-0.399 * * *$ \\
\hline & $(0.032)$ & $(0.089)$ & $(0.005)$ & $(0.002)$ & $(0.068)$ & $(0.039)$ & $(0.174)$ \\
\hline \multirow{2}{*}{$\begin{array}{l}\text { Risk attitude } \\
\text { in finance }\end{array}$} & $-0.149 *$ & -0.180 & $-0.164 *$ & -0.048 & -0.167 & $-0.375 * * *$ & $-0.207 * *$ \\
\hline & $(0.032)$ & $(0.030)$ & $(0.041)$ & $(0.003)$ & $(0.032)$ & $(0.143)$ & $(0.059)$ \\
\hline \multirow{2}{*}{$\begin{array}{l}\text { Risk attitude in } \\
\text { Leisure }\end{array}$} & $-0.295 * * *$ & -0.189 & -0.065 & -0.149 & $-0.382 * *$ & -0.122 & $-0.401 * * *$ \\
\hline & $(0.106)$ & $(0.025)$ & $(0.006)$ & $(0.026)$ & $(0.105)$ & $(0.016)$ & $(0.179)$ \\
\hline $\begin{array}{l}\text { Risk attitude } \\
\text { in career }\end{array}$ & -0.030 & -0.040 & -0.003 & 0.056 & $-0.356^{* * *}$ & -0.127 & $-0.329 * * *$ \\
\hline \multirow{2}{*}{$\begin{array}{l}\text { Risk attitude } \\
\text { in health }\end{array}$} & -0.061 & -0.227 & 0.080 & -0.029 & 0.009 & -0.035 & $-0.152 *$ \\
\hline & $(0.006)$ & $(0.055)$ & $(0.010)$ & $(0.001)$ & $(0.000)$ & $(0.002)$ & $(0.034)$ \\
\hline \multirow{2}{*}{$\begin{array}{l}\text { Risk attitude } \\
\text { in education }\end{array}$} & -0.005 & -0.049 & -0.014 & 0.069 & $-0.184 *$ & 0.014 & $-0.221 * * *$ \\
\hline & $(0.000)$ & $(0.003)$ & $(0.000)$ & $(0.008)$ & $(0.045)$ & $(0.000)$ & $(0.079)$ \\
\hline \multirow[t]{2}{*}{300 Y Res Prob } & 0.004 & -0.004 & -0.003 & 0.001 & -0.007 & 0.001 & $-0.013 * * *$ \\
\hline & $(0.000)$ & $(0.005)$ & $(0.006)$ & $(0.000)$ & $(0.023)$ & $(0.000)$ & $(0.095)$ \\
\hline \multirow[t]{2}{*}{600 Y Res. Prob. } & -0.002 & -0.010 & -0.001 & -0.003 & -0.005 & 0.002 & $-0.013 * * *$ \\
\hline & $(0.002)$ & $(0.039)$ & $(0.000)$ & $(0.007)$ & $(0.014)$ & $(0.002)$ & $(0.106)$ \\
\hline \multicolumn{8}{|l|}{ Win 100 Y Res. } \\
\hline \multirow[t]{2}{*}{ Prob. } & 0.042 & 0.003 & 0.082 & 0.105 & 0.093 & -0.012 & $-0.254 * * *$ \\
\hline & $(0.003)$ & $(0.000)$ & $(0.013)$ & (0.019) & $(0.012)$ & $(0.000)$ & $(0.105)$ \\
\hline \multicolumn{8}{|l|}{ Loose 100 Y Res. } \\
\hline Prob. & -0.109 & $-0.231 *$ & 0.011 & 0.013 & -0.186 & -0.020 & $-0.233 * * *$ \\
\hline
\end{tabular}

Note: *** $\mathrm{p}<0.01,{ }^{* *} \mathrm{p}<0.05,{ }^{*} \mathrm{p}<0.1$. In “( )” “Nagelkerke R. Square”. For dependent variables (1)-(5), we use Binary logit models, by taking “often” and “sometimes”as “0”; “never”as “1”. For dependent variables (6) and (7), we use Ordered Probit models. 
Table 6 Regression results for risk attitude in relation to personal characteristics

\begin{tabular}{|c|c|c|c|c|c|c|c|c|c|c|c|c|}
\hline & $\begin{array}{c}\text { Lottery } \\
\text { Reservation } \\
\text { Price }\end{array}$ & $\begin{array}{c}\text { Lottery } \\
\text { Reservation } \\
\text { Probability }\end{array}$ & $\begin{array}{l}\text { General } \\
\text { risk } \\
\text { attitude }\end{array}$ & $\begin{array}{c}\text { Risk } \\
\text { attitude } \\
\text { in finance }\end{array}$ & $\begin{array}{c}\text { Risk } \\
\text { attitude in } \\
\text { leisure }\end{array}$ & $\begin{array}{c}\text { Risk } \\
\text { attitude in } \\
\text { career }\end{array}$ & $\begin{array}{c}\text { Risk } \\
\text { attitude } \\
\text { in health }\end{array}$ & $\begin{array}{c}\text { Risk } \\
\text { attitude in } \\
\text { education }\end{array}$ & $\begin{array}{c}300 \text { Yuan } \\
\text { Lottery } \\
\text { Game }\end{array}$ & $\begin{array}{c}600 \text { Yuan } \\
\text { Lottery } \\
\text { Game }\end{array}$ & $\begin{array}{l}\text { Win } 100 \\
\text { Yuan } \\
\text { Game }\end{array}$ & $\begin{array}{c}\text { Loose } \\
100 \text { Yuan } \\
\text { Game }\end{array}$ \\
\hline \multirow[t]{2}{*}{ Female } & -30.325 & 5.486 & -0.453 & $-0.953 * *$ & -0.037 & -0.106 & -0.479 & -0.131 & -4.913 & -7.354 & 0.320 & 0.283 \\
\hline & (35.776) & (3.987) & $(0.427)$ & $(0.462)$ & $(0.463)$ & $(0.511)$ & $(0.497)$ & $(0.537)$ & (10.036) & (11.010) & $(0.551)$ & $(0.478)$ \\
\hline \multicolumn{13}{|l|}{ Major } \\
\hline \multirow[t]{2}{*}{ Humanities } & 63.054 & $10.139 * *$ & $0.983^{* *}$ & $1.324^{* *}$ & -0.424 & -0.139 & -0.321 & 0.751 & 5.904 & 5.411 & 0.454 & 0.197 \\
\hline & (41.590) & (4.635) & $(0.497)$ & (0.538) & $(0.538)$ & $(0.594)$ & $(0.578)$ & $(0.624)$ & (11.667) & (12.799) & $(0.640)$ & $(0.555)$ \\
\hline \multirow[t]{2}{*}{ Social Studies } & 16.656 & 4.465 & 0.098 & 0.378 & -0.246 & -0.394 & -0.596 & -0.086 & -9.669 & -7.343 & 0.888 & 0.025 \\
\hline & (35.946) & (4.006) & $(0.429)$ & $(0.465)$ & $(0.465)$ & $(0.513)$ & $(0.500)$ & (0.539) & (10.084) & (11.062) & $(0.553)$ & $(0.480)$ \\
\hline \multicolumn{13}{|l|}{ Family income } \\
\hline less than five & 1.353 & -1.228 & $-3.115^{* * *}$ & $-2.826^{* * *}$ & -0.233 & -1.124 & 0.599 & 0.055 & -9.195 & 14.395 & -0.396 & -0.769 \\
\hline thousand & (73.754) & (8.219) & $(0.881)$ & (0.953) & $(0.954)$ & (1.053) & (1.026) & (1.107) & $(20.690)$ & (22.697) & (1.136) & $(0.985)$ \\
\hline five to twenty & 8.723 & 0.953 & $-2.419 * * *$ & $-1.662 *$ & -0.713 & -1.209 & -0.516 & -0.111 & -0.124 & 5.893 & -0.590 & -1.152 \\
\hline thousand & (70.664) & (7.875) & $(0.844)$ & (0.913) & (0.915) & (1.009) & $(0.983)$ & $(1.060)$ & (19.823) & $(21.747)$ & $(1.088)$ & $(0.943)$ \\
\hline twenty to fifty & 37.109 & 0.408 & $-3.031 * * *$ & $-1.990 * *$ & -0.299 & -1.173 & -0.144 & 0.073 & -15.140 & -6.329 & -0.360 & -0.770 \\
\hline thousand & (74.567) & (8.309) & $(0.891)$ & $(0.964)$ & $(0.965)$ & (1.064) & (1.037) & (1.119) & (20.918) & (22.984) & (1.148) & (0.995) \\
\hline fifty to one hundred & 57.153 & -7.939 & -1.500 & -1.139 & 0.021 & -0.597 & -0.290 & 0.208 & -1.181 & 8.381 & -1.301 & -1.109 \\
\hline thousand & $(82.412)$ & (9.184) & (0.985) & (1.065) & (1.067) & (1.176) & $(1.146)$ & (1.237) & (23.119) & $(25.362)$ & (1.269) & (1.100) \\
\hline \multicolumn{13}{|l|}{ Study rank $\square$} \\
\hline \multirow[t]{2}{*}{ First 25\% } & -8.845 & 3.845 & $-2.274 * * *$ & $-2.084 * *$ & -1.401 & -1.388 & 1.264 & -1.046 & -7.432 & 4.551 & -0.467 & -1.374 \\
\hline & $(68.154)$ & (7.595) & $(0.814)$ & $(0.881)$ & $(0.882)$ & $(0.973)$ & $(0.948)$ & (1.023) & (19.119) & $(20.974)$ & (1.049) & $(0.910)$ \\
\hline \multirow[t]{2}{*}{ Middle high 25\% } & 44.861 & -2.707 & $-1.726^{* *}$ & $-1.582^{*}$ & -0.866 & -0.557 & 1.254 & -0.682 & -18.017 & -11.625 & -0.292 & -0.748 \\
\hline & (63.894) & (7.120) & $(0.763)$ & $(0.826)$ & $(0.827)$ & $(0.912)$ & $(0.888)$ & (0.959) & (17.924) & (19.663) & $(0.984)$ & $(0.853)$ \\
\hline \multirow[t]{2}{*}{ middle low 25\% } & 45.079 & -3.210 & $-2.079 * * *$ & -1.128 & -1.188 & -0.611 & 0.640 & -0.533 & -7.200 & -0.981 & 0.010 & -0.113 \\
\hline & (63.531) & (7.080) & $(0.759)$ & $(0.821)$ & $(0.822)$ & (0.907) & $(0.883)$ & (0.953) & (17.822) & (19.551) & $(0.978)$ & $(0.848)$ \\
\hline $\mathrm{R}^{2}$ & $6.10 \%$ & $14.90 \%$ & $22.10 \%$ & $18.50 \%$ & $6.70 \%$ & $6.70 \%$ & $7.80 \%$ & $3.40 \%$ & $5.50 \%$ & $5.40 \%$ & $4.60 \%$ & $6.80 \%$ \\
\hline
\end{tabular}


Graph 1: Lottery Reservation Prices (Win 1000 yuan at 10\%).

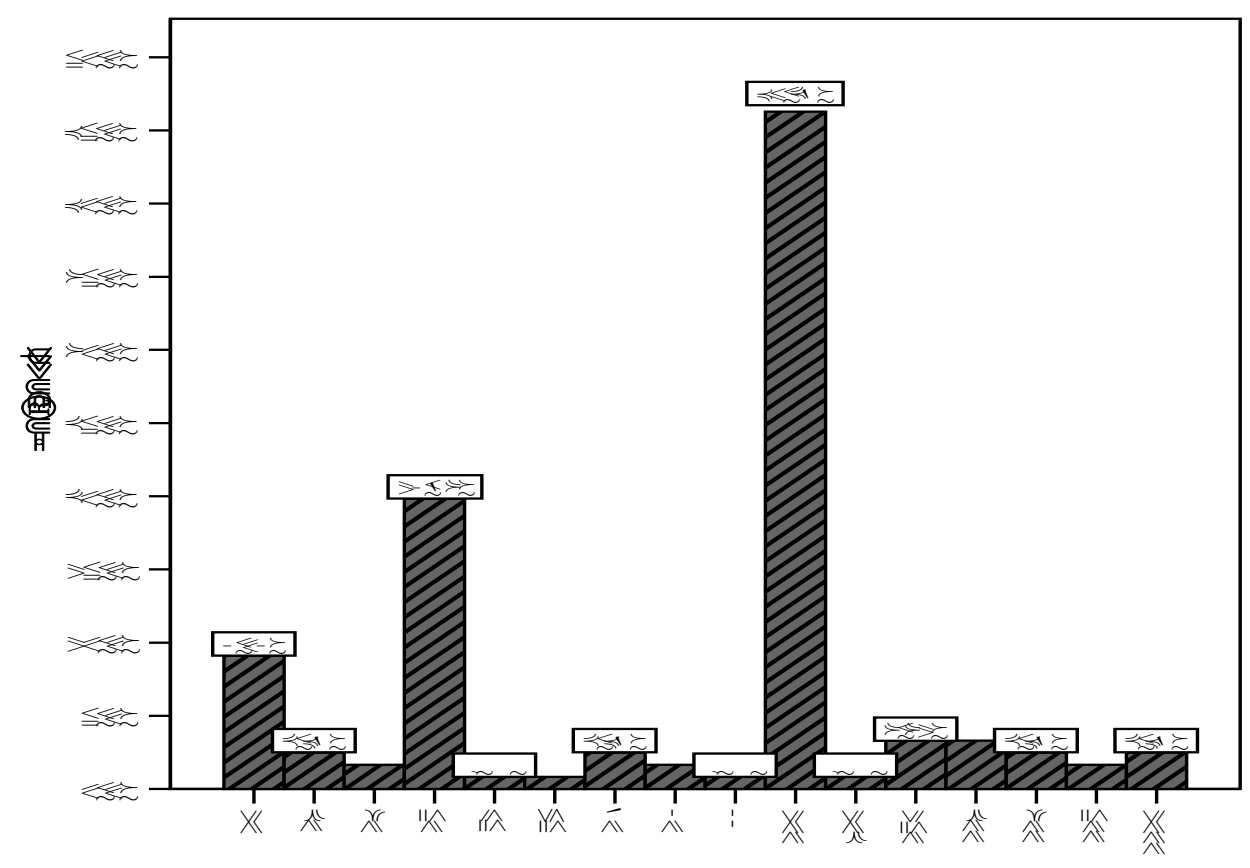

Reservation price for a ticket in the lottery

Graph 2: Lottery Reservation Probabilities (2000 yuan prize or 100 yuan cash)

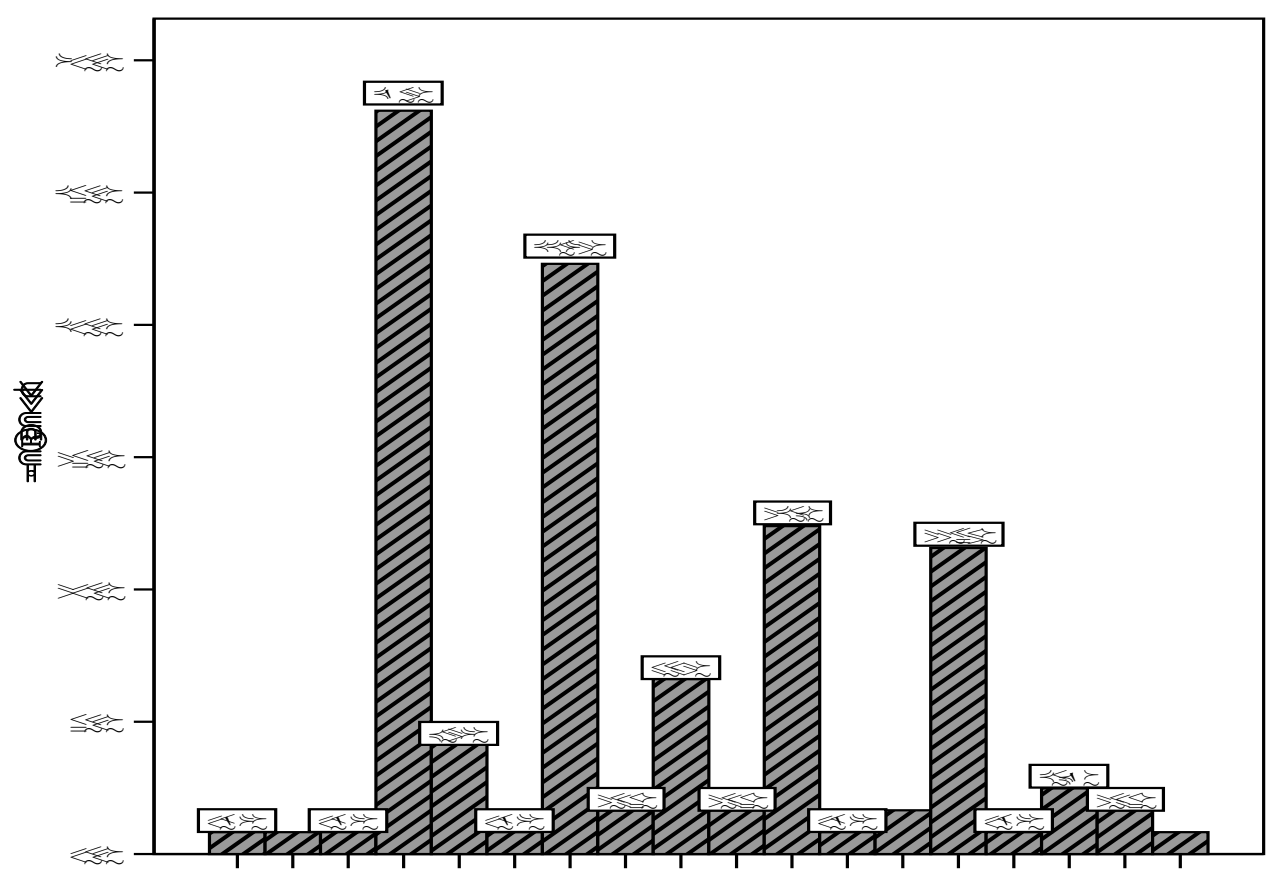

Reservation probability for a ticket in the lottery. 
Graph 3: Relative frequencies for general risk attitude

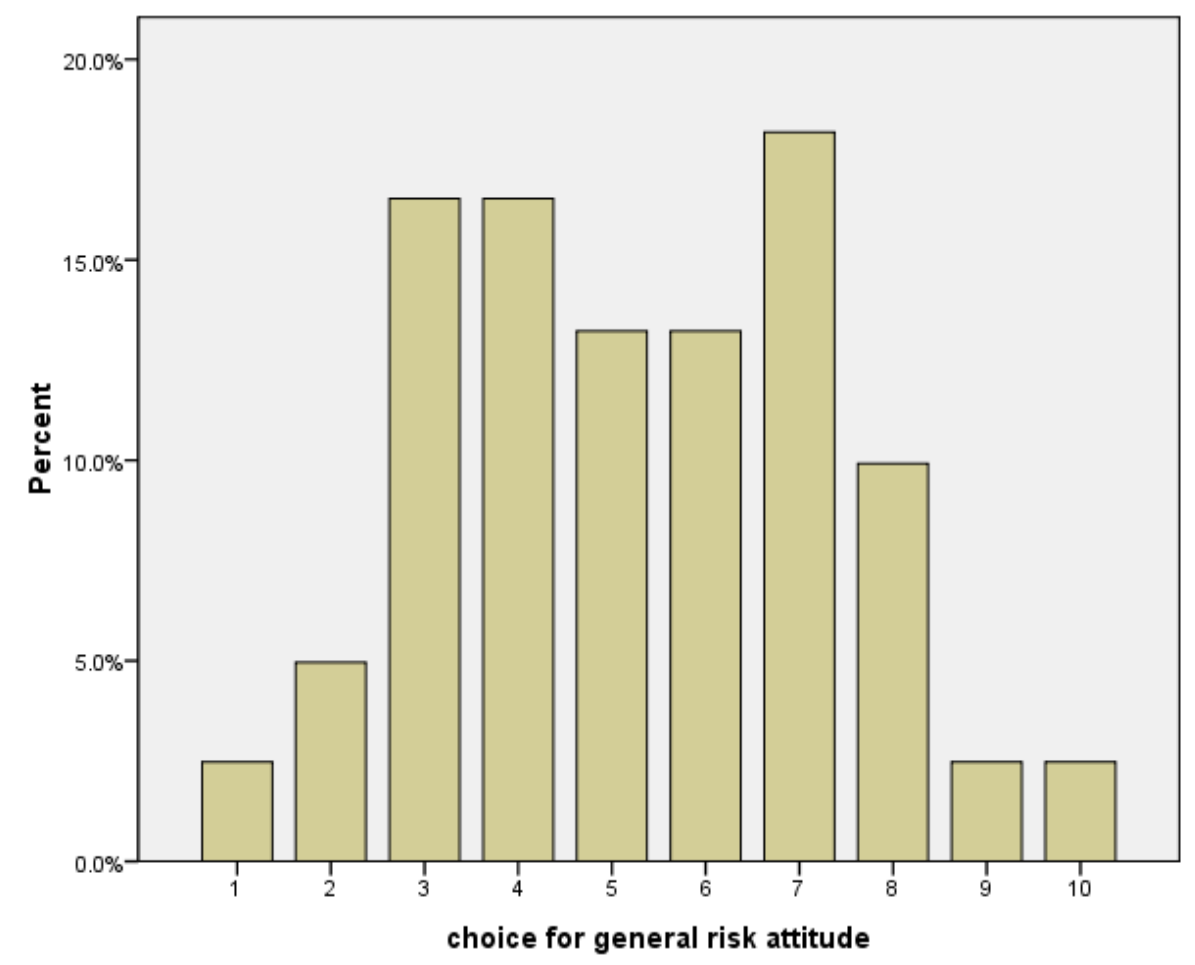

Graph 4: Relative frequencies for risk attitude in finance

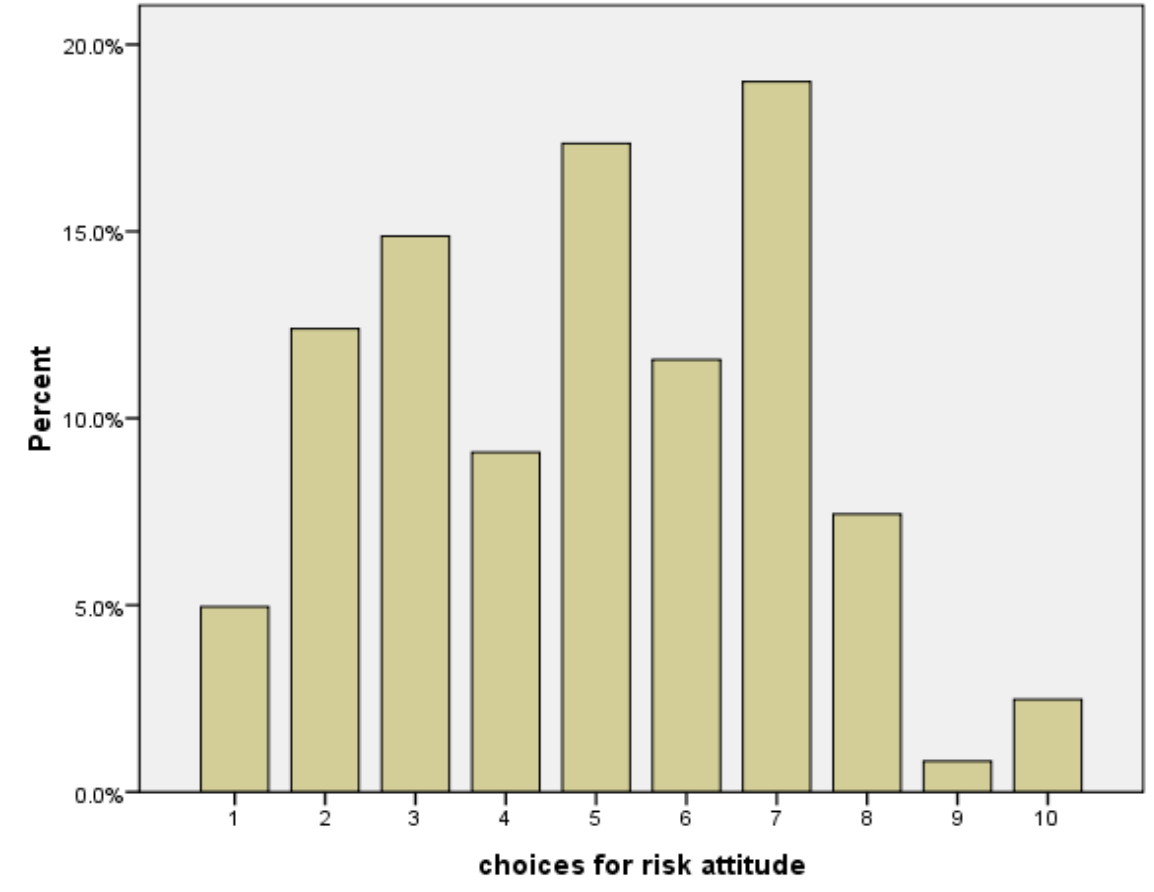


Graph 5: Relative frequencies for risk attitude in leisure

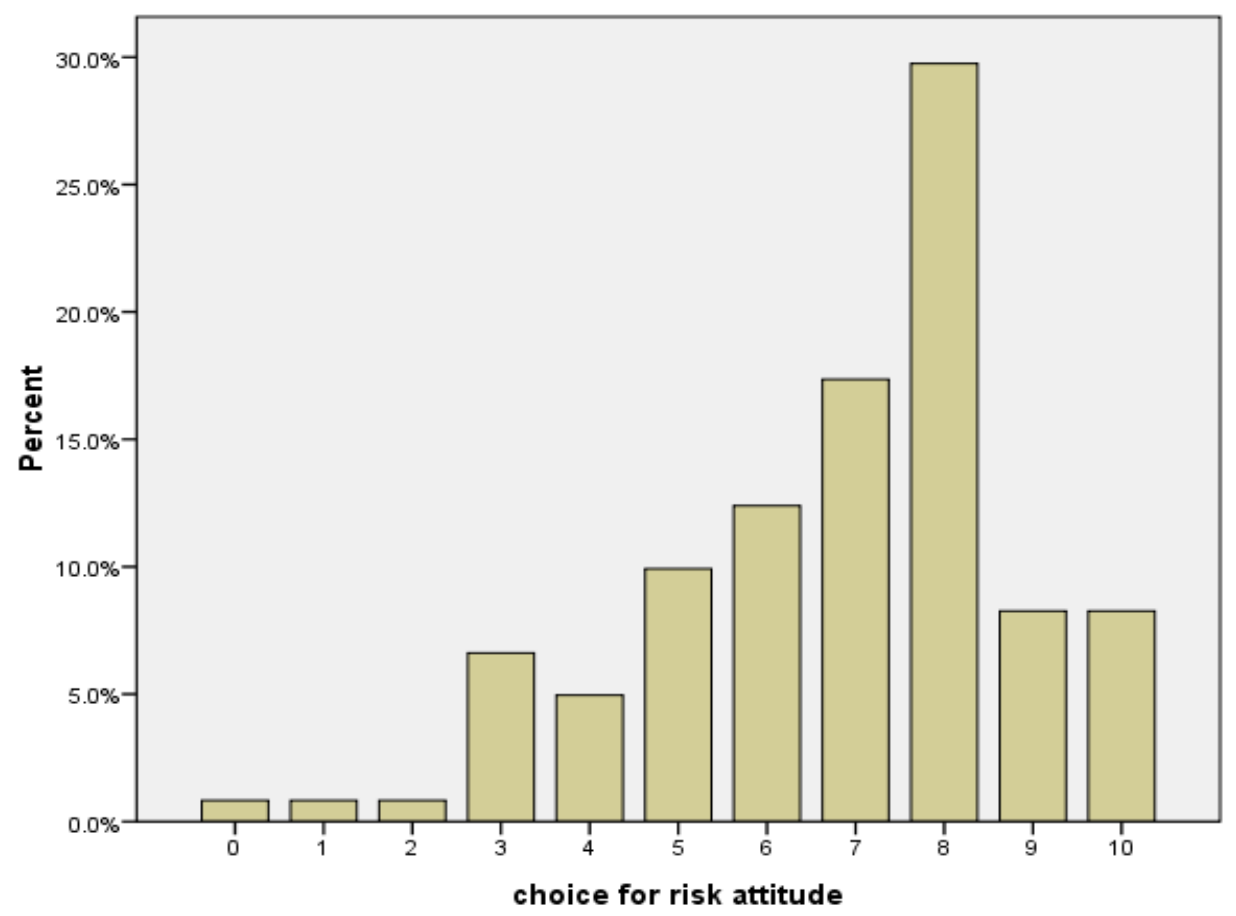

Graph 6: Relative frequencies for risk attitude in career

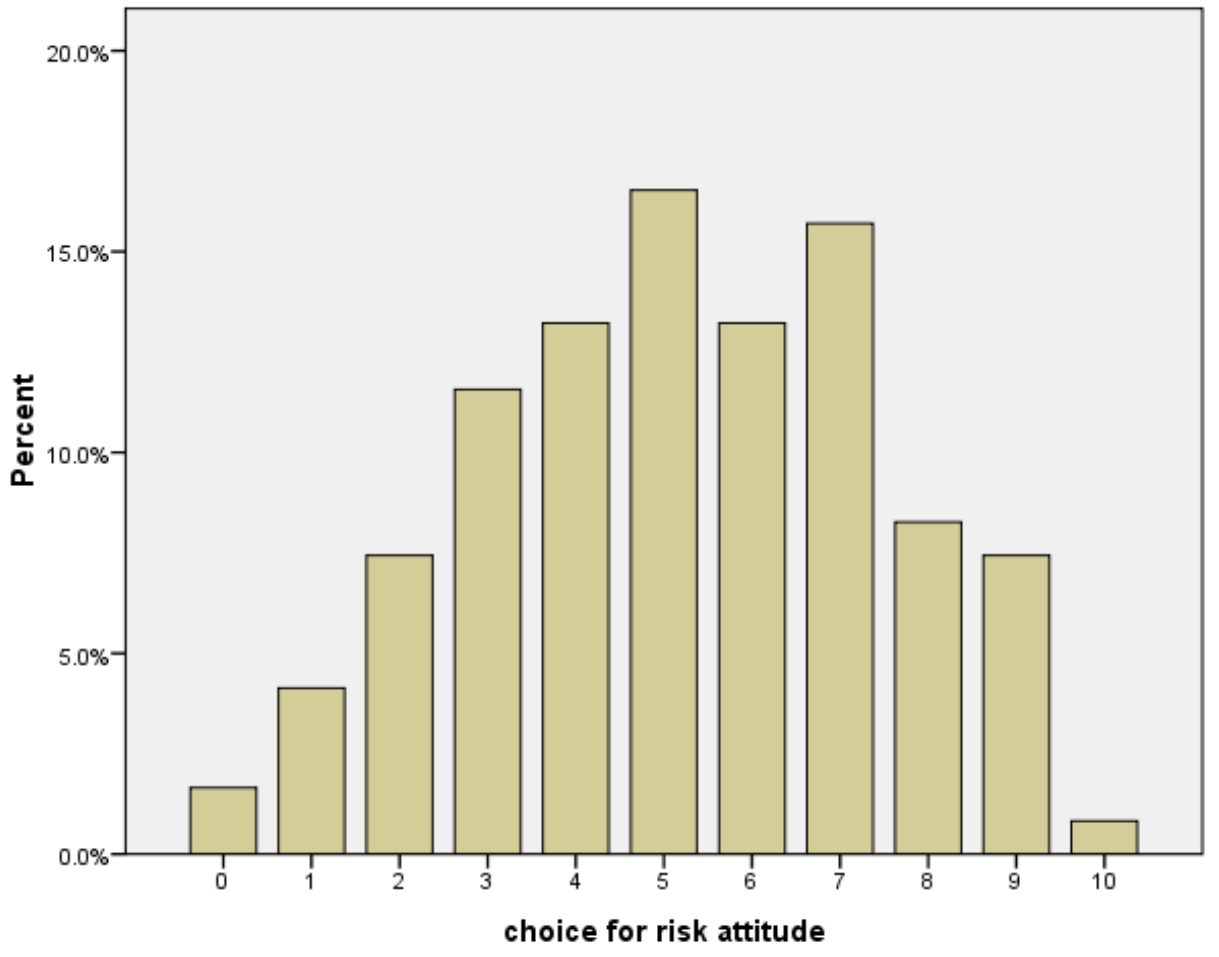


Graph 7: Relative frequencies for risk attitude in health

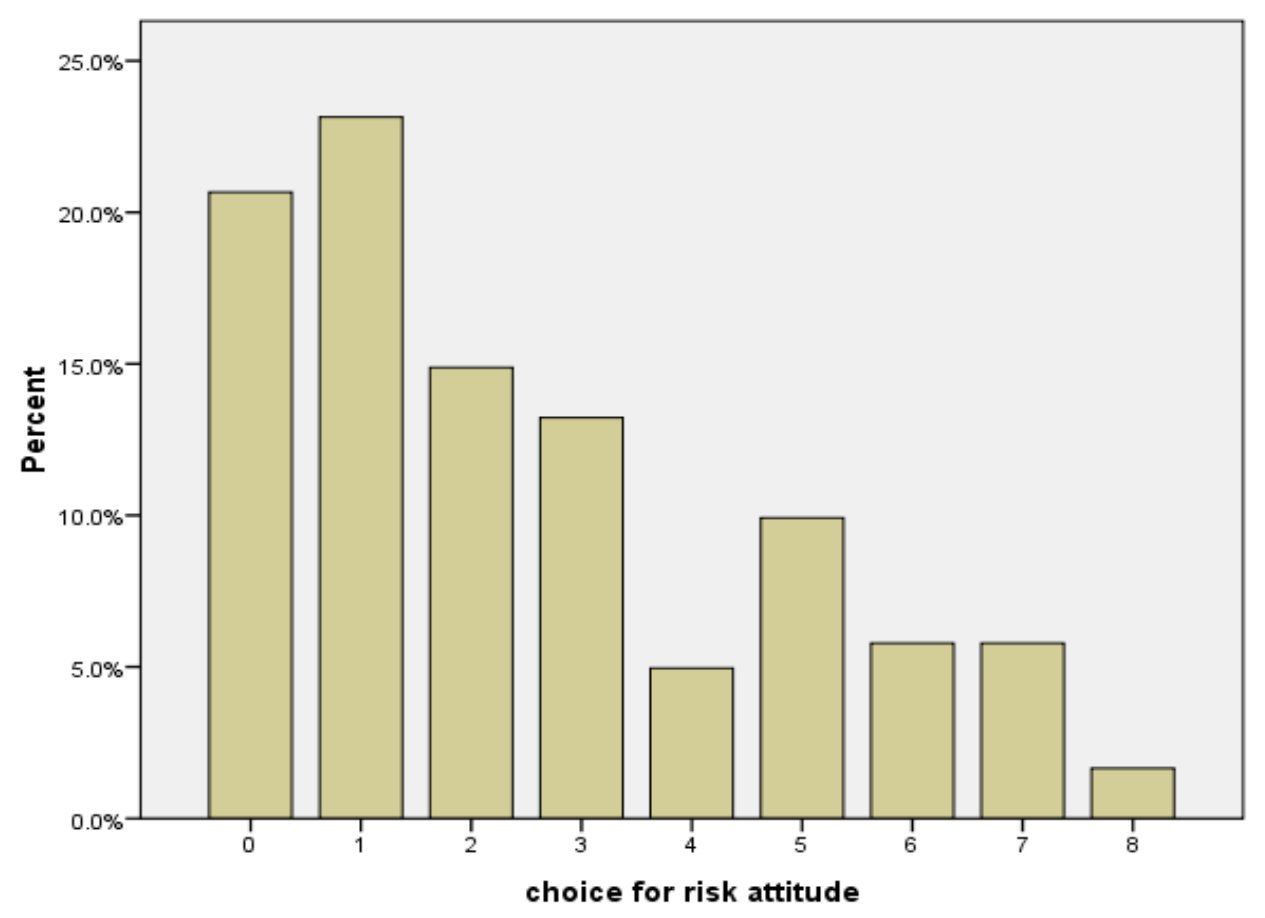

Graph 8: Relative frequencies for risk attitude in education

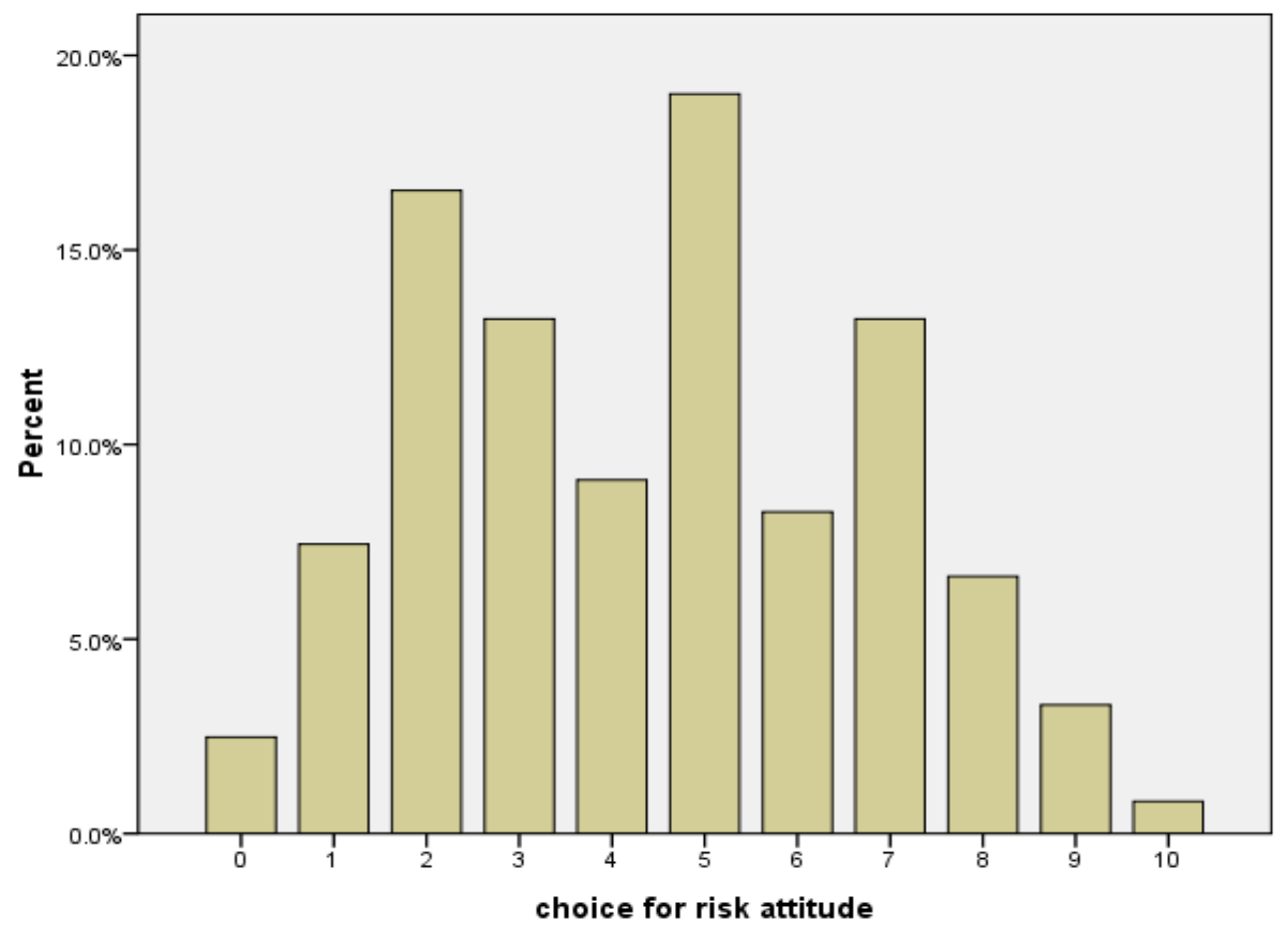


Graph 9: Choices for reservation price in 300 Yuan Game

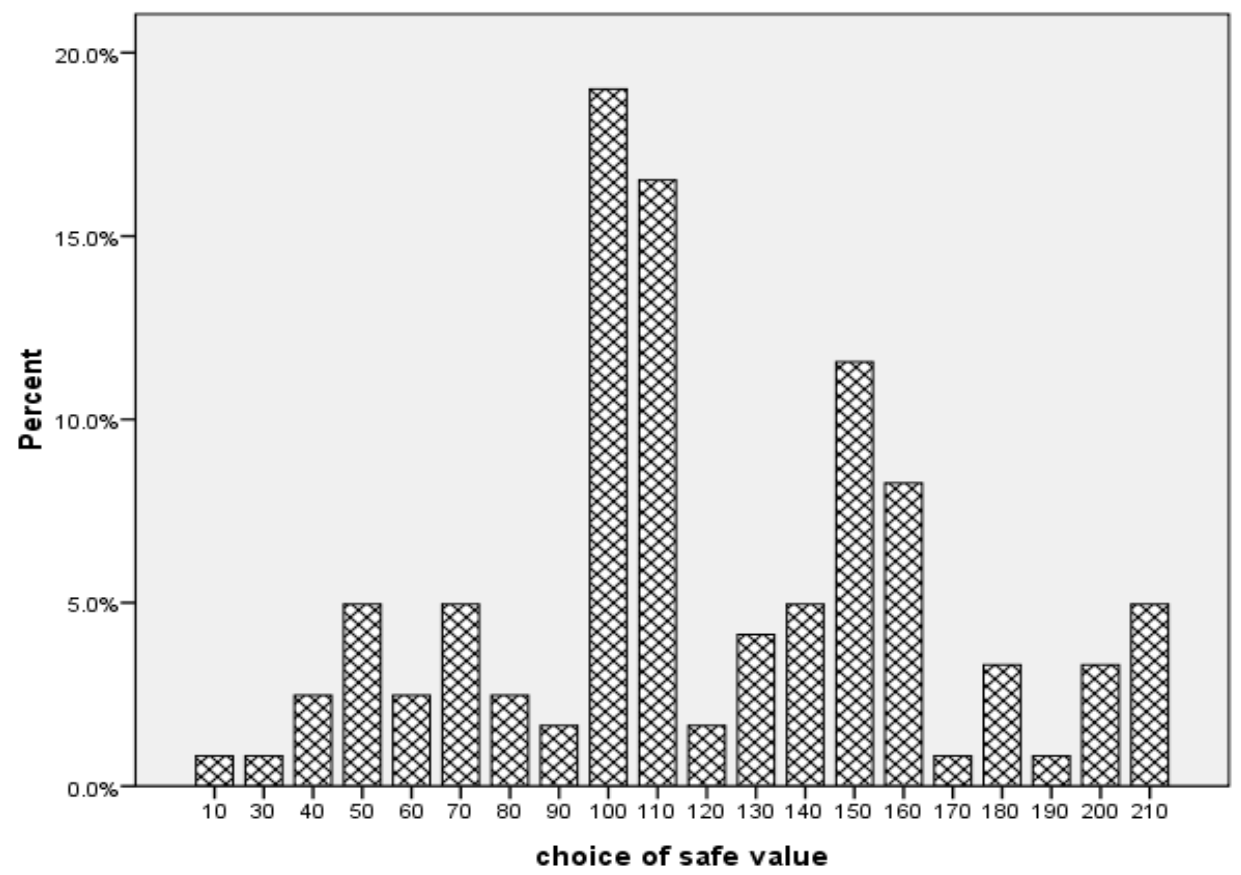

Note: $\square 210 \square$ means the individual will always choose to play games whatever the safety value is. 


\section{Graph 10: Choices for reservation price in 600 Yuan Game}

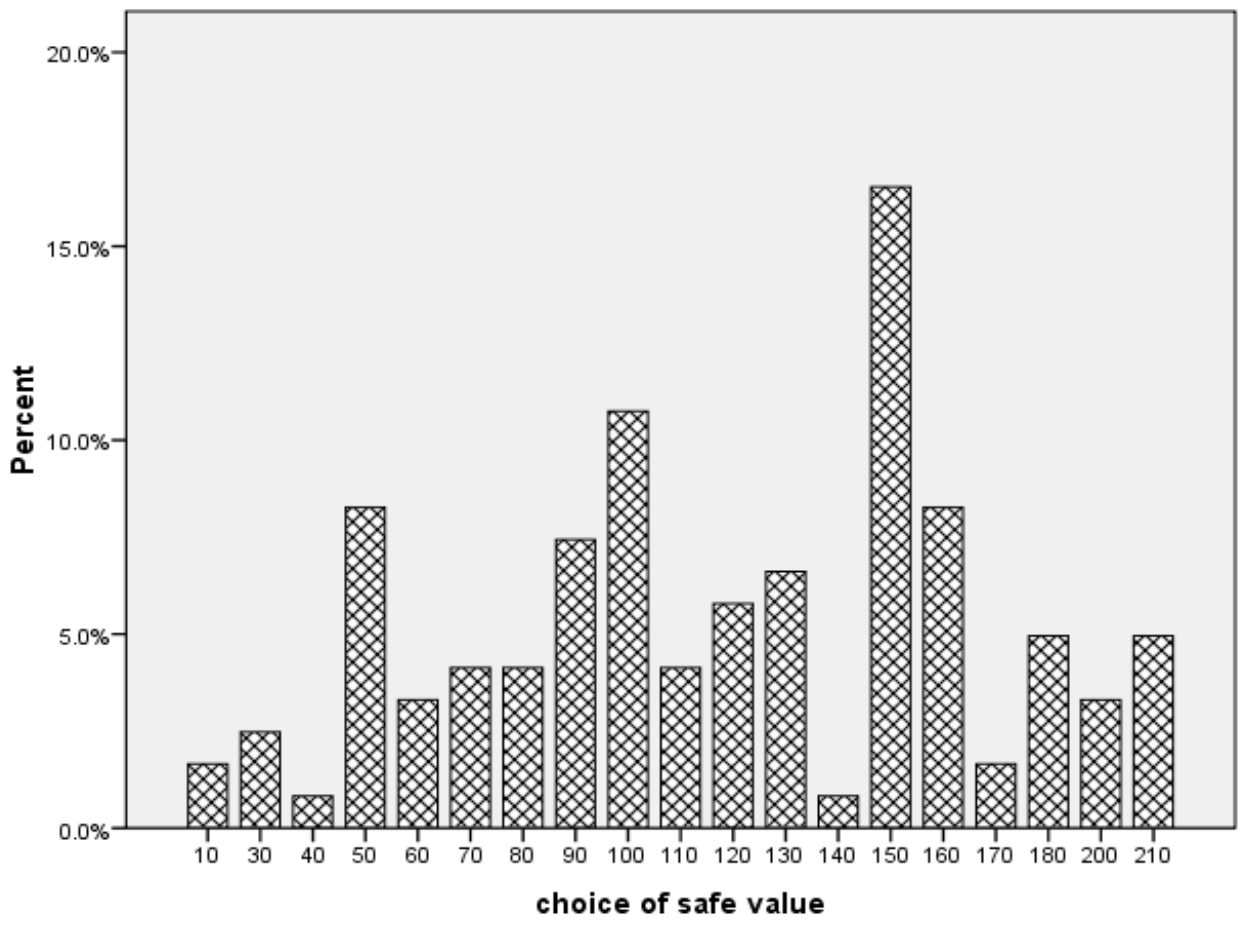

Note: $\square 210 \square$ means the individual will always choose to play games whatever the safety value is. 
Graph 11: Choices for reservation probability in Win 100 Yuan Game

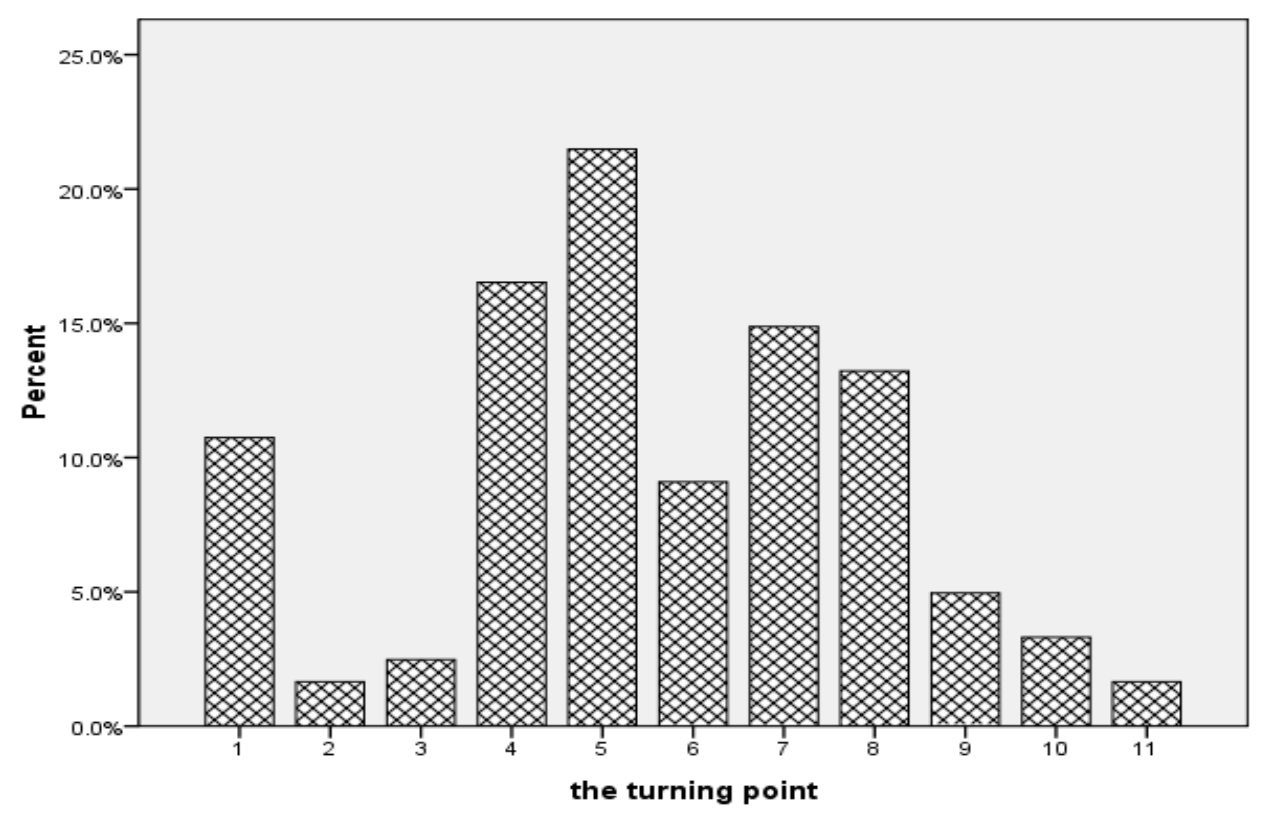

Note: $\square 11 \square$ means the individual will never choose to play games whatever the probability of winning 100 yuan is.

Graph 12: Choices for reservation probability in Loose 100 Yuan Game

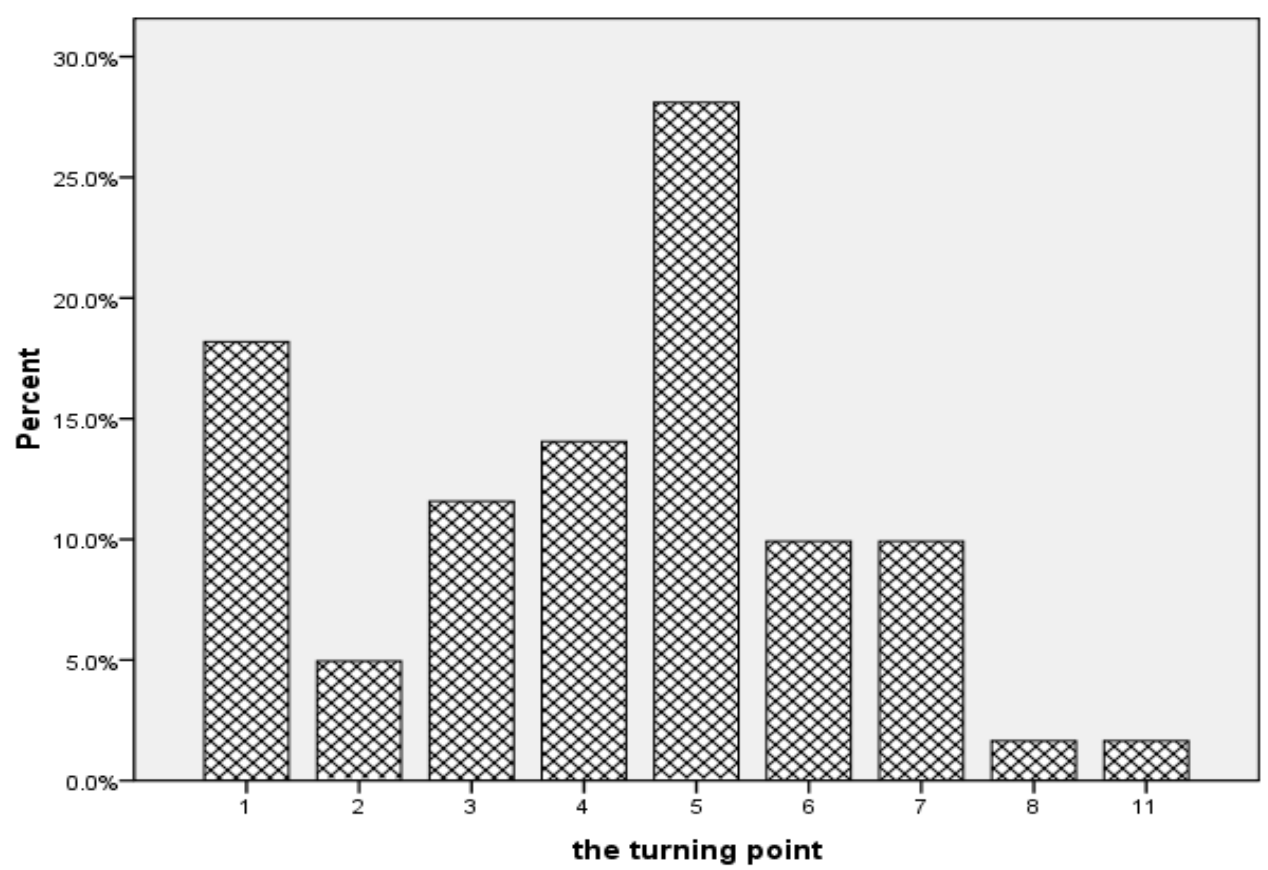

Note: $\square 11 \square$ means the individual will always choose to play games whatever the probability of loosing 100 yuan is. 


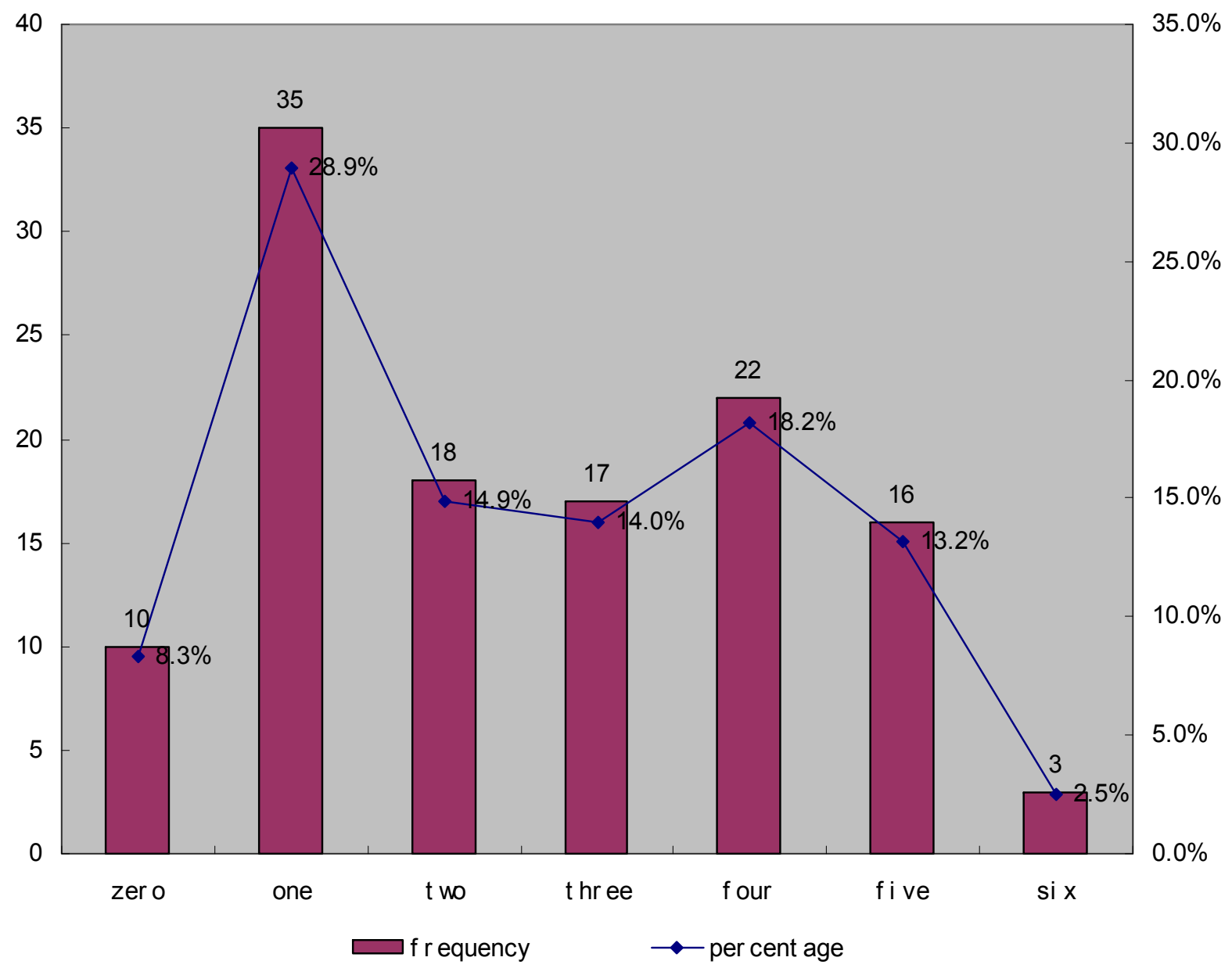


